Anita Kotak, Senior Registrar in Psychiatry, St Charles Hospital, London; *Ann Elaine Arnold, Consultant Old Age Psychiatrist, and Peter Frost. Consultant in Chemical Pathology. Park Royal
Centre for Mental Health, Central Middlesex Hospital, Acton Lane, London NW10 7NS

*Correspondence

\title{
Trainee attitudes within the Faculty of the Psychiatry of Learning Disability
}

\author{
Sue Carvill, Geoff Marston and Sheila Hollins
}

\begin{abstract}
Aims and method Recruitment of trainees and consultants into psychiatry is a major concern. A questionnaire survey of trainees within the psychiatry of learning disability was conducted to highlight attitudes about training and career issues.

Results Ninety per cent of trainees decided on a career in learning disability as a result of completing a junior post in this speciality. Forty-three per cent were seeking dual accreditation and nearly half of these were experiencing problems relating to this; $84 \%$ expressed fears about becoming a consultant; and 53\% felt they needed more advice on how to find a consultant post.

Clinical implications Increased exposure to learning disability at the basic training grade is required to ensure recruitment. In addition issues related to dual accreditation and anxieties about consultant posts need to be addressed.
\end{abstract}

Within the National Health Service (NHS) there is a national shortfall in consultant recruitment. Within psychiatry, this shortfall has now reached alarming proportions. In 1996, the NHS Executive in conjunction with the Royal College of Psychiatrists and the National Association of Health Authorities and Trusts (NAHAT) convened a working party to address the medical staffing shortage in psychiatry (Jenkins \& Scott, 1998). It highlighted areas that could be addressed to improve recruitment and consultant morale, and gave a series of action points for the short. medium and long term. The Collegiate Trainees Committee (CTC) is also looking at possible solutions to improving morale and recruitment within the trainee body.
Within the Faculty of the Psychiatry of Learning Disability recruitment problems in the recent past have seemed near crisis point. A recent survey of the 161 trusts providing learning disability services (Cooper \& Bailey, 1998) showed that consultants are covering excessively large population bases, compared to the estimated need of one consultant per 100000 population (Royal College of Psychiatrists, 1992). Many regional specialist registrars training schemes have been short of trainees, some having no one in post.

The Department of Health estimates an annual retirement rate of 5.5 consultants in learning disability psychiatry, and has no expectations of expansion. With 19 specialist registrar (SpRs) due to obtain Certificates of Completion of Specialist Training (CCSTs) in 1998 there appears to be a shortage of consultant posts. However, within the speciality the picture is rather different with many consultant posts remaining vacant and unadvertised because of previous failed attempts to recruit. At the same time other trusts are seeking to increase their consultant establishment, recognising the complexity of this specialist role in modern services. In the foreseeable future there will be more than enough consultant posts for those entering specialist training.

The aim of this survey was to attempt to assess the attitudes of SpR and senior registrar trainees within the Faculty of the Psychiatry of Learning Disability with regard to training issues, career choice and concerns about the future. The hope was to identify their needs and concerns, which in turn might help direct thinking towards how best to tackle recruitment issues. 


\section{The study}

Attitudes were assessed by an anonymous, 16item questionnaire (available from the authors upon request). This used a combination of open questions about aspects of training and career choice, along with more direct questions about specific aspects of training (e.g. supervision) which demanded a qualitative rating (e.g. from poor to excellent).

The questionnaire was administered by two routes. It was personally given to all $\mathrm{SpRs}$ and senior registrars attending an annual meeting for trainees in the psychiatry of learning disability $(n=30)$, and by post to those unable to attend $(n=31)$. All identified trainees within the UK and Ireland were contacted.

In the absence of an official database, we attempted to ascertain an estimate of the current numbers of trainees working within the UK/ Ireland via contact with scheme organisers and local trainee representatives.

\section{Findings}

Our estimate of the national total of senior registrars and SpRs in learning disabilities was 61. Response from the conference was total $(n=30)$, with $68 \%$ replying to the postal survey $(n=21)$, giving an overall response rate of $84 \%(n=51)$.

The length of training to date ranged from four months to 4.5 years for the part-timers $(n=8)$, and 0 to 4.5 years for the full-timers. Forty-two trainees had chosen learning disabilities as their career at registrar level, four at senior house officer level, two after a senior registrar locum in learning disabilities, two as medical students and one prior to medical school. Fifteen people (29\%) had some working or personal experience with those with learning disabilities prior to doing psychiatry, with one known to have a relative with learning disability.

Identified features which helped people to decide on learning disability as a career are shown in Table 1. Other features specified by respondents included the wide variety of specialist areas within learning disabilities such as forensic and child psychiatry and the excellent research opportunities as well as negative aspect of other specialities. Forty-eight (94\%) were pleased with their choice of learning disability.

Twenty-two (43\%) of the trainees were seeking dual accreditation of which half were in general psychiatry, five in child and adolescent, three in forensic, two in psychotherapy and one in neuropsychiatry. Out of those seeking dual accreditation, nearly half stated that they had encountered problems which included moving goal posts/uncertain rules, tutors being opposed to their career plans, excessively long training and problems with funding. Twenty-five (49\%) expressed fears about the future of learning disability psychiatry. Common fears included it being squeezed out or absorbed into general psychiatry, recruitment problems and unfilled posts resulting in a decline of services, social services taking a greater role, learning disability psychiatry not being recognised in Europe, consultant numbers being reduced and further funding cuts.

How trainees rated their training is shown in Table 2 . Time was regularly protected for research for 47 (92\%), special interests for 44 (86\%) and individual supervision for $41(80 \%)$ trainees.

Fifteen (29\%) expressed concerns about eventually finding a consultant post and 24 (41\%) stated that they were concerned about finding a suitable post in their area. Other concerns included a perceived lack of subspeciality posts within learning disability (e.g. forensic learning disability psychiatry) and not having enough time at the point of obtaining a CCST to make a proper decision.

Forty-three $(84 \%)$ indicated some fears about becoming a consultant, particularly becoming overwhelmed with an excessive overload; increasing responsibility with diminishing support; management commitments and isolation. Features influencing trainees in choosing a consultant post are shown in Table 3. It can be seen that the two most important factors were having a peer group and access to in-patient facilities.

Twenty-seven (53\%) trainees felt that they were not receiving sufficient advice about how to find an appropriate consultant post. Areas in which they felt they needed help included what to look for in a job, having the opportunity to meet and talk to new consultants, being able to decode job advertisements and job descriptions and knowing about regional variations in services.

\section{Comment}

It is disappointing that the Higher Specialist Training Committee has no database of senior

Table 1. Features helping decision on learning disability as a career (\%)

\begin{tabular}{lccc}
\hline & Yes & No & No answer \\
\hline Interesting client group & 92 & 2 & 6 \\
Clinical challenge & 86 & 8 & 6 \\
$\begin{array}{l}\text { Experience as registrar in } \\
\text { learning disability }\end{array}$ & 69 & 27 & 4 \\
Less onerous 'on call' rota & 53 & 37 & 10 \\
Less stressful workload & 35 & 47 & 18 \\
$\begin{array}{l}\text { Greater avallabillty of } \\
\quad \text { consultant posts }\end{array}$ & 29 & 55 & 16 \\
$\begin{array}{l}\text { Better availability of } \\
\text { part-time posts }\end{array}$ & 8 & 72 & 20 \\
\hline
\end{tabular}


Table 2. How trainees rated their training (\%)

\begin{tabular}{|c|c|c|c|c|c|}
\hline & Excellent & Good & Average & Poor & Very poor \\
\hline Audit & 6 & 27 & 51 & 16 & - \\
\hline Management & 10 & 37 & 43 & 6 & 2 \\
\hline Support in research & 20 & 37 & 23 & 16 & 4 \\
\hline Teaching & 6 & 61 & 25 & 6 & 2 \\
\hline Supervision of clinical work & 15 & 53 & 20 & 8 & - \\
\hline Academic programme & 16 & 47 & 27 & 6 & 4 \\
\hline Clinical experience & 37 & 53 & 10 & - & - \\
\hline
\end{tabular}

Table 3. Factors influencing choice of consultant post (\%)

\begin{tabular}{llllll}
\hline & A lot & Some & Not much & Not at all & No answer \\
\hline Lack of consultant peers & 71 & 27 & 0 & 0 & 2 \\
Presence/absence of in-patient facilities & 59 & 27 & 8 & 2 & 4 \\
Presence/absence of junior trainees & 39 & 39 & 18 & 2 & 2 \\
Location rural/urban & 33 & 39 & 18 & 6 & 4 \\
Greater than average salary & 14 & 35 & 39 & 10 & 2 \\
\hline
\end{tabular}

registrars/SpRs in post in learning disability psychiatry, or information about the overall number. As recruitment problems to the $\mathrm{SpR}$ grade are well recognised and were expressed as a concern among trainees, a central record would be very useful in enabling the speciality to monitor recruitment trends.

The results highlighted that the vast majority of trainees choose learning disability as their specialist career only after doing a senior house officer/registrar post. A recent survey of Part 2 MRCPsych candidates revealed that little more than a quarter had any experience of learning disability. In order to increase exposure, consideration has been given to making learning disability a compulsory component of basic training. The College Council has recently directed that from April 2000 all trainees will be required to have a minimum of six months fulltime training in either child and adolescent psychiatry or the psychiatry of learning disability, or a combination of both. (Collegiate Trainees' Committee Newsletter No. 1, 1998; available upon request from Postgraduate Educational Services, Royal College of Psychiatrists, 17 Belgrave Square, London SW1X 8PG). Schemes failing to provide suitable access to these posts should be considered for dis-accreditation. Increasing learning disabilities profile in the MRCPsych Part 2 examination and ensuring candidates have a reasonably high chance of seeing a person with a learning disability in the clinical examination, might act as an incentive for trainees to insist on clinical experience. Establishing an appropriate learning disability service as a Part 2 examination centre might be one way of achieving this.
The results indicate that dual certification is quite commonly being sought (42\%). Nearly half of trainees are encountering problems. Lack of appropriate local posts as well as moves between trusts and national training numbers have caused confusion. One way to improve this would be to encourage trainees to gain single accreditation, without fear that employment opportunities will be restricted. For those who do pursue dual accreditation there is a need to ensure that 'common interest' posts are equally recognised in each speciality. This is particularly important in psychotherapy, forensic and child and adolescent psychiatry.

Training in learning disability was rated as good to average for most aspects except clinical experience which was largely excellent to good. Despite this many cited anxieties about their training being inadequate to prepare them for becoming a consultant. Protected time for research, special interest and individual supervision was the norm for most, but not all trainees. Supervision was variable which suggests there should be a more effective way of monitoring and improving trainer standards.

About a third of the trainees had some concerns about finding the right consultant post. Given the failure of some trusts to recruit consultants it is hoped that the College guidelines (Royal College of Psychiatrists, 1997) on job descriptions and the Faculty's advice on the consultant role and facilities required by consultants will be helpful to trust managers in creating more attractive posts in the future.

Some also expressed anxieties about eventually becoming a consultant. Many of these concerns were probably common to senior registrars/SpRs 
in all specialities, except possibly with respect to a fear of isolation. Because of the replacement of long-stay hospitals with community-based services, isolation has become a particular problem for consultants in the psychiatry of learning disability. This was further highlighted by the fact that $71 \%$ would be cautious about choosing a consultant post where there were no consultant colleagues. This factor may discriminate against certain types of post, for example those in rural locations or in small trusts.

Planned mergers of many small NHS trusts in the near future may contribute to an improvement in this aspect. Another possible remedy might be to encourage the development of trusts more specialised in learning disability work, providing both in-patient and community services. By serving a larger population base on a sub-regional basis, more consultants would be working together under the same employer, facilitating support and communication. It would also allow better continuity of care and further specialisation of service development (e.g. providing tertiary 'centres of excellence' in autism/epilepsy, or mentally disordered offenders).

Despite the various concerns it was reassuring to see that the majority of respondents $(94 \%)$ were pleased with their choice of learning disability as a career. The results indicated that important factors were the clinical challenge and the interesting client group, with only $14 \%$ being influenced by salary enticements. The high number of questionnaires returned also indicated a keen interest by trainees in their training and future.

It would seem that trainees welcome regular annual conferences, such as those offered by the
Faculty, but that these should also address training issues and provide regular advice such as how to find the right consultant post. We hope that the recent College Council directive will improve recruitment into the Faculty.

\section{Acknowledgements}

Thank you to all the trainees who took the time to return the questionnaires.

\section{References}

COOPER, S. A. \& BAILEY, N. (1998) Psychiatrists and the learning disabilities health service. Psychiatric Bulletin. 22, 25-28.

Jenkins, J. \& ScOTT, J. (1998) Medical staffing crisis in psychiatry. Psychiatric Bulletin, 22, 239-241.

ROYAL COLLEGE OF PSYCHIATRISTS (1992) Mental Health of the Nation: The Contribution of Psychiatry (Councll Report CR16). London: Royal College of Psychiatrists.

- (1997) Model Consultant Job Descriptions (Occasional Paper OP39). London: Royal College of Psychiatrists. - (1998) Higher Specialist Training Handbook (Occasiona Paper OP43). London: Royal College of Psychiatrists.

*Sue Carvill, Senior Registrar in the Psychiatry of Learning Disability. Geoff Marston, Senior Registrar in the Psychiatry of Learning Disability, West Midlands Rotational Training Scheme, Monyhull Hospital, Monyhull Hall Road, King's Norton, Birmingham B3O 3QB; and Sheila Hollins, Chair of the Faculty of the Psychiatry of Learning Disability. Head of the Department of Psychiatry of Disability. St George's Hospital Medical School, London

*Correspondence

\section{Psychotherapy experience in Ireland}

\section{Siobhan Rooney and Gabrielle Kelly} Aims and method A questionnaire was sent to
members of the Psychotherapy Section of the Irish
Dlvision of the Royal College of Psychiatrists to assess
psychotherapy training.
Results Members from Northern Ireland, compared
with those from the Republic, had more mandatory

Psychiatric Bulletin (1999), 23, 89-94 psychotherapy experience in a variety of psychotherapies, had attended more lectures on the theories of the psychotherapies, had cases longer in analysis and were more satisfied with their level of supervision. Few non-consultant hospital doctors had obtained mandatory psychotherapy training as outlined by the 